\title{
Metakaolin-Based Geopolymers for Targeted Adsorbents to Heavy Metal Ion Separation
}

\author{
Francisco J. López ${ }^{1,2}$, Satoshi Sugita², Motohiro Tagaya1, Takaomi Kobayashi' \\ ${ }^{1}$ Department of Materials Science and Technology, Nagaoka University of Technology, Nagaoka, Japan \\ ${ }^{2}$ Departament of Chemestry, Universidad de Guanajuato, Guanajuato, Mexico \\ Email: takaomi@nagaokaut.ac.jp
}

Received 12 May 2014; revised 10 June 2014; accepted 2 July 2014

Copyright (C) 2014 by authors and Scientific Research Publishing Inc.

This work is licensed under the Creative Commons Attribution International License (CC BY). http://creativecommons.org/licenses/by/4.0/

(c) (i) Open Access

\begin{abstract}
Geopolymer adsorbents were prepared from silica and metakaolin in different $\mathrm{Al}$ and Si components and applied for removal of metal ions, $\mathrm{Cs}^{+}$and $\mathrm{Pb}^{2+}$, from other heavy metal ions mixture. The geopolymer was optimized at $\mathrm{Si} / \mathrm{Al}=2$ as adsorbent, targeting to $\mathrm{Cs}^{+}$and $\mathrm{Pb}^{2+}$ separation. The binding behavior was well fitted to Langmuir model, which proved that the metakaolin-based geopolymer had multibinding to adsorb ions. The effective adsorption was also observed independent of $\mathrm{NaCl}$ concentration for the $\mathrm{Cs}^{+}$and $\mathrm{Pb}^{2+}$. This meant that the ion adsorption of geopolymers occurred under non-electrostatic mechanism.
\end{abstract}

\section{Keywords}

\section{Geopolymer, Metakaolin, Silica Fume, Metal Ions, Adsorption}

\section{Introduction}

The presence of the toxic metals generated by mineral processing in industries causes a major hazard to the water environment [1]. Thus, serious regulations are required to establish in many countries to remove effectively the toxic metal ions from the waste waters prior to discharge into natural environment. Also, metal ions are non-biodegradable materials and excessive levels can be damaging to human organism. The contamination of metal ions has a serious influence on the public health. Therefore, the elimination of metal ions from industrial waste to water is necessary to solve the environment of water cleaning. During the last few years, the common methods available to remove metal ions from waste water are coagulation, chemical precipitation, ion-exchange, and reverse osmosis [2]. In addition, the adsorption techniques present excellent qualities for treating industrial 
waste waters containing metal ions, when solid adsorbents are employed for recovery of metal ions as lead, copper, cadmium, nickel and zinc [3] [4]. Therefore, in the approach to replace the conventional adsorbents, geopolymers are a new strategy for decontamination of metal ions from waste water, which are composed of silica and alumina similar to zeolite material [5]-[9]. For this reason, the geopolymers has begun to develop as adsorbent materials in the process of removal metal ions from the waste water as an alternative to the industrial sector [9]. It is known that geopolymers are alkali activated aluminosilicates, consisting of a solid reactive component that contains $\mathrm{SiO}_{2}$ and $\mathrm{Al}_{2} \mathrm{O}_{3}$, for example, fly ashes, active clays, pozzolanas and slags [10] [11]. The alkaline activation solution for geopolymerization process contains alkali hydroxides, silicates, aluminates, carbonates, and sulphates or combinations thereof [10]. Several researches used metakaolin as ideal raw material for manufacture geopolymers [12] [13] because of its high reactivity and purity compared to other clays [14][16]. Here, zeolite which presents crystalline nature is well known as representative solid adsorbent for metal ions. Noticing is very meaningful that geopolymers have an amorphous three-dimensional structure constituted by $\mathrm{SiO}_{4}$ and $\mathrm{AlO}_{4}$ tetrahedra and can be prepared at lower temperature than zeolites. These geopolymers would be expected to have the unique properties as well as zeolite adsorbents. Furthermore, the geopolymers became an important subject in the following properties: compressive strength of the matrix and resistance to acid attack, freezing and heat thaw cycles. Such characteristic makes them interesting products for adsorbents as used with concrete replacements in various environments. If geopolymers can actually remove metal ions from waste water via adsorption, the regenerated matrix could become new approach for several industries. Consequently, this affects both the environment and societies positively [17]-[19]. However, existing literature on the adsorption of heavy metals using geopolymers is very little. Among them, Xu et al. reported the conversion of fly ash to geopolymer was investigated under different conditions for adsorbents. It was paid great attention as a potential material that geopolymers showed removal of $\mathrm{Cd}, \mathrm{Ni}, \mathrm{Pb}$ (II), $\mathrm{Cu}$ (II), phosphate, $\mathrm{NO}_{\mathrm{x}}$, boron, fluoride, radionuclide of ${ }^{137} \mathrm{Cs}$ and ${ }^{90} \mathrm{Sr}$, and dyes [20] [21]. However, the details about geopolymer adsorbents still are not well known at this time. In the present work, the main aim is synthesis of amorphous geopolymers from metakaolin and silica fume in order to use the materials as adsorbents for decontamination of heavy metal ions including $\mathrm{Cs}^{+}$and $\mathrm{Pb}^{2+}$. The preparation and metal adsorption of the geopolymers were focused in different $\mathrm{Si}$ and $\mathrm{Al}$ amounts in the resultant matrix. The adsorption behavior was examined in a mixture of aqueous solution in detail for targeted separation of $\mathrm{Cs}^{+}$and $\mathrm{Pb}^{2+}$ ions.

\section{Experimental}

\subsection{Materials and Geopolymer Synthesis}

The metakaolin (MK) was produced by the calcination of the kaolinite $\left[\mathrm{Al}_{2} \mathrm{Si}_{2} \mathrm{O}_{5}(\mathrm{OH})_{4}\right]$ at $700^{\circ} \mathrm{C}$ for $5 \mathrm{~h}$ [22] [23] and was used as $\mathrm{Al}_{2} \mathrm{O}_{3}$ source for the synthesis of geopolymers. Also, silica fume AEROSIL 380 purchased from EVONIK industries was used. The role of adding silica fume was to support the sufficient amount of $\mathrm{SiO}_{2}$ on the resulting geopolymers. For the alkaline activator, aqueous sodium hydroxide (NaOH) was mixed with the silica fume $\left(\mathrm{SiO}_{2}\right)$ using a ratio of $\mathrm{Na} / \mathrm{Si}=0.6$. Figure 1 shows the illustration of synthesis protocol of metakaolin based geopolymer. MK was mixed in aqueous $\mathrm{NaOH} 8 \mathrm{M}$ using a ball mill for $5 \mathrm{~h}$ with ratio of $\mathrm{H}_{2} \mathrm{O} / \mathrm{Na}_{2} \mathrm{O}=$ 20. Here, the molar ratio between $\mathrm{SiO}_{2}$ and $\mathrm{Al}_{2} \mathrm{O}_{3}$ was changed at $\mathrm{Si} / \mathrm{Al}=1,2,3$, 4, and 5. Then, the mixed pastes were casting into $20 \mathrm{~mm}$ latex cube molds and vibrated for $5 \mathrm{~min}$ to release the airs bubbles. The geopolymer pastes were cured at $80^{\circ} \mathrm{C}$ for $12 \mathrm{~h}$ to start condensation reaction. Upon removal from the molds, the resultant geopolymers were placed in an oven at $200^{\circ} \mathrm{C}$ for $12 \mathrm{~h}$ in order to complete the polycondensation. Principal composition of raw materials for geopolymers is presented in Table 1.

\subsection{Characterization of Resultant Metakaolin Based Geopolymers}

The obtained geopolymers were washed several times by deionized water in order to remove the excess of sodium hydroxide. After drying, the samples were crushed and sieved using a 120 mesh to control a particle size range. Before the adsorption tests of metal ions, the powder samples were characterized by FT-IR spectroscopy for determination of molecular vibration of the geopolymers, X-ray diffractometer (XRD) for crystal structure determination, X-ray fluorescence (XRF) in order to know chemical composition of principal components and Scanning electron microscopy (SEM) was used for evaluation of geopolymers morphology. The Brunauer-Emmer-Teller (BET) surface area was measured by a $\mathrm{N}_{2}$ adsorption-desorption after drying at $200^{\circ} \mathrm{C}$ and the 


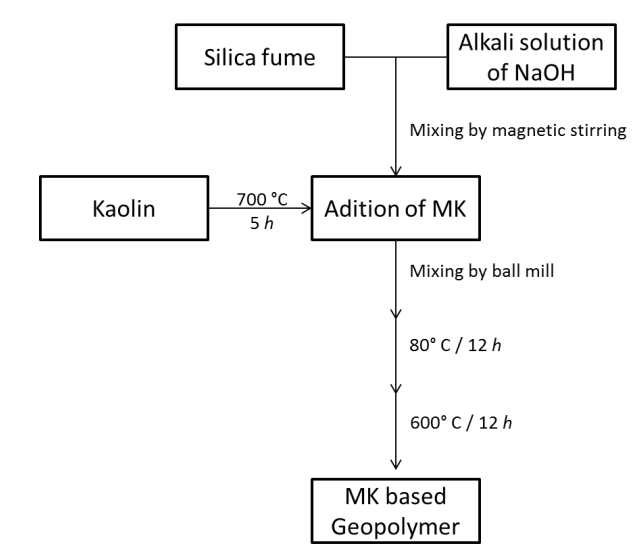

Figure 1. Synthesis protocol of metakaolin based geopolymer.

Table 1. Chemical composition of the metakaolin-based geopolymer adsorbent.

\begin{tabular}{cccccccc}
\hline Element & Silica fume & $\mathrm{MK}$ & $\mathrm{GP}-1$ & $\mathrm{GP}-2$ & $\mathrm{GP}-3$ & $\mathrm{GP}-4$ & $\mathrm{GP}-5$ \\
\hline $\mathrm{SiO}_{2}$ & 99.9 & 52.0 & 48.4 & 60.2 & 65.3 & 72.3 & 73.7 \\
$\% \mathrm{Al}_{2} \mathrm{O}_{3}$ & 0.01 & 42.8 & 41.2 & 26.4 & 18.7 & 16.3 & 12.7 \\
$\% \mathrm{Fe}_{2} \mathrm{O}_{3}$ & -- & 0.6 & 0.56 & 0.69 & 0.75 & 0.83 & 0.85 \\
$\% \mathrm{CaO}$ & -- & 0.2 & 0.19 & 0.23 & 0.25 & 0.29 & 0.28 \\
$\% \mathrm{MgO}$ & -- & -- & --- & -- & -- & -- & -- \\
$\% \mathrm{~K}_{2} \mathrm{O}$ & -- & 0.5 & 0.46 & 0.58 & 0.63 & 0.69 & 0.71 \\
$\% \mathrm{Na}_{2} \mathrm{O}$ & -- & 0.6 & 1.92 & 7.53 & 6.29 & 6.2 & 5.96 \\
$\% \mathrm{TiO}_{2}$ & 0.01 & 1.2 & 1.12 & 1.39 & 1.51 & 1.67 & 1.70 \\
\hline
\end{tabular}

zeta potential was measured on a potentiometer (ELSZ1NGK Photal Otsuka Electronics instrument) in the absence and presence of $5 \mathrm{wt} \%$ and $10 \mathrm{wt} \%$ of $\mathrm{NaCl}$ at $\mathrm{pH} 5$.

\subsection{Adsorption Tests of Geopolymers for Heavy Metal Ions}

The adsorption experiments of the geopolymers were performed by the batch system at $25^{\circ} \mathrm{C}$ and $\mathrm{pH} 5$. Multicomponent aqueous solutions containing $\mathrm{Cs}^{+}, \mathrm{Pb}^{2+}, \mathrm{Cu}^{2+}, \mathrm{Cd}^{2+}, \mathrm{Ni}^{2+}$ and $\mathrm{Zn}^{2+}$ were chiefly prepared from analytical grade standard solutions (Nakarai Teque, Japan) in the range of 50 to $500 \mathrm{mg} / \mathrm{L}$. The initial $\mathrm{pH}$ of the heavy metal solution was controlled to $\mathrm{pH} 5$ with adjusting amounts of $\mathrm{HCl} 0.1 \mathrm{M}$ and $\mathrm{NaOH} 0.1 \mathrm{M}$ for each adsorption test. Then $0.05 \mathrm{mg}$ of geopolymer powder was added in $40 \mathrm{ml}$ of the multicomponent aqueous solution of metal ions. After adsorption batch, the supernatant liquid was separated by centrifugation at $100 \mathrm{rpm}$. The changes in the metal ion contents in the supernatant were analyzed by atomic absorption spectroscopy (AA6300 SHIMADZU). The changes in metal ion concentration of the solution were represented as the removal of metal ion by geopolymer adsorption, according to following equation.

$$
q_{e}=\frac{\left(C_{0}-C_{e}\right) V}{W}
$$

where $C_{0}$ and $C_{e}$ are the initial and equilibrium concentrations (ppm), respectively, of the metal ion in the solution, $V$ is the volume (L), and $W$ is the weight (mg) of the adsorbent.

\section{Results and Discussions}

\subsection{Properties of Geopolymer Adsorbents}

Table 2 shows the surface area (BET), zeta potential at pH 5 and bulk density of the metakaolin based geopo- 
Table 2. Composition and condition of geopolymer synthesis* .

\begin{tabular}{cccccccc}
\hline Sample & $\mathrm{Si} / \mathrm{Al}$ & $\mathrm{Na} / \mathrm{Si}$ & $\mathrm{H}_{2} \mathrm{O} / \mathrm{Na}_{2} \mathrm{O}$ & $\mathrm{Si} / \mathrm{Al}$ by XRF & $\mathrm{BET}\left[\mathrm{m}^{2} / \mathrm{g}\right]$ & $\zeta$-Potential at $\mathrm{pH}=5[\mathrm{mV}]$ & Bulk density $\left[\mathrm{g} / \mathrm{cm}^{3}\right]$ \\
\hline GP-1 & 1 & 0.7 & 20 & 0.99 & 27.5 & -20.0 & 0.8 \\
GP-2 & 2 & 0.7 & 20 & 1.91 & 3.3 & -29.0 & 0.68 \\
GP-3 & 3 & 0.7 & 20 & 2.84 & 2.3 & -29.0 & 1.09 \\
GP-4 & 4 & 0.7 & 20 & 3.72 & 1.9 & -29.0 & 1.41 \\
GP-5 & 5 & 0.7 & 20 & 4.86 & 2.1 & -28.3 & 1.23 \\
\hline
\end{tabular}

${ }^{*}$ The curing temperature for the condentation was carried out at $80^{\circ} \mathrm{C}$ for 12 hours and thend cured matrix was again heated at $200^{\circ} \mathrm{C}$ for 6 hours.

lymers. By using the chemical composition by XRF data we estimated Si/Al ratio in the geopolymers after the polycondensation reaction and it was observed that the values of the ratio were close to the calculated in the beginning. This meant that the polycondensation of MK and silica fume was performed to be geopolymer framework under the described conditions. SEM pictures are shown in Figure 2, the resultant geopolymers with a ratio Si/Al > 4 were condensed like a dense matrix as seen in Figure 2(d) and Figure 2(e). The morphology suggested that the grain size of the geopolymers was decreased with increasing the amount of silica in the framework. Correspondingly, the surface area BET was higher in the GP-1 than those of others due to the high Al content in the geopolymer. Also, an increase of the bulk density was observed, leading the decreasing of the porosity in the samples.

FTIR spectra are shown in Figure 3. The spectral data of MK and silica fume used as raw materials were included. The spectral differences in the FTIR results were found in the low-wavenumber region between 800 to $400 \mathrm{~cm}^{-1}$ and the middle-wavenumber region between 1250 to $800 \mathrm{~cm}^{-1}$. In the low-wavenumber region, the spectrum of silica fume had characteristic the bands at $469 \mathrm{~cm}^{-1}$ assigned to Si-O tetrahedral bending vibration [24] and the MK band at $461 \mathrm{~cm}^{-1}$ and $812 \mathrm{~cm}^{-1}$ assigned to tetrahedral bending mode of T-O ( $\mathrm{T}=\mathrm{Si}$ or $\left.\mathrm{Al}\right)$ and bending mode of Si-O-Al [25]-[27], respectively. After geopolymerization, both intensities of these two bands decreased and the new band appeared at about $710 \mathrm{~cm}^{-1}$. The spectral data indicated that the formation of tetrahedral $\mathrm{Al}\left[\mathrm{Al}-\mathrm{O}_{4}\right]$ was found in the resultant geopolymers [27]. The small band appearing around $1400 \mathrm{~cm}^{-1}$ was related to the asymmetric stretching of the O-C-O bonds of $\mathrm{CO}_{3}{ }^{2-}$ due to atmospheric carbonation on the surface of powdered products [28]. The absorption bands at $1650 \mathrm{~cm}^{-1}$ were for $\mathrm{H}-\mathrm{OH}$ vibration, corresponding to the presence of water in the geopolymer [25] [26]. Moreover, the small band centered about $600 \mathrm{~cm}^{-1}$ was caused by T-O-Si symmetric stretching vibrations [29] [30]. In the mid-wavenumber region, a shift in the broad band position for Si-O-Si of silica fume at $1099 \mathrm{~cm}^{-1}$ and Si-O-T from MK at $1084 \mathrm{~cm}^{-1}$ was seen toward $1000 \mathrm{~cm}^{-1}$. Both assigned asymmetric stretching peaks were seen in the geopolymer as assigned to Si-O-Al of geopolymer vibration at $1000 \mathrm{~cm}^{-1}$ [31]-[33]. This band shift suggested strongly formation of geopolymers [34] [35]. Especially, at higher $\mathrm{Si} / \mathrm{Al}$ ratio, the Si-O-Si band at $1099 \mathrm{~cm}^{-1}$ was observed in the broad band as shoulder.

Furthermore, the XRD pattern in Figure 4 supported the amorphous features of the geopolymers. As seen, the silica fume and MK used had broad peak centered at $22^{\circ}$ in the XRD patterns. The presence of the sharp peak at $26^{\circ}$ implied that the MK contained crystalline $\mathrm{SiO}_{2}$ and mica components. After the alkali activation of the starting materials, the scattering diffraction of the broad peak was shifted from $\sim 22^{\circ}$ to $\sim 28^{\circ}$ in $2 \theta$. This was evidence of the change in the local bonding environment due to the arrangement of the structure during the polycondensation process.

Table 2 contains the zeta potential obtained from the geopolymers at $\mathrm{pH}$ of 5 . The values of zeta potential are shown in Figure 5. It was possible to observe that the zeta potential decreased from $-20 \mathrm{mV}$ to $-29 \mathrm{mV}$ when the $\mathrm{Si} / \mathrm{Al}$ ratio was increased from 1 to 5 , respectively, at $\mathrm{pH}$ 5. This meant that the increment in the silica content in the framework caused negatively changed groups of ${\mathrm{O}-\mathrm{Si}-\mathrm{O}^{-}}^{-}$in the geopolymer [36] [37] for the corresponding surface charges expressed. As shown in Figure 5, the values of zeta potential increased, when $\mathrm{NaCl}$ concentration increased at $5 \mathrm{wt} \%$ and $10 \mathrm{wt} \%$. The zeta potential increased with the increment of $\mathrm{SiO}_{2}$ and a constant value was obtained after the ratio of $\mathrm{Si} / \mathrm{Al}=2$, for the three $\mathrm{NaCl}$ concentrations. In other hand, it was observed the zeta potential decrease with the increment of concentration of $\mathrm{NaCl}$ of $5 \%$ and $10 \%$ due to the competitive adsorption of $\mathrm{H}^{+}$with $\mathrm{Cl}^{-}$for the binding sites of geopolymers at $\mathrm{pH}$. For example at $\mathrm{Si} / \mathrm{Al}=2$, each value of 


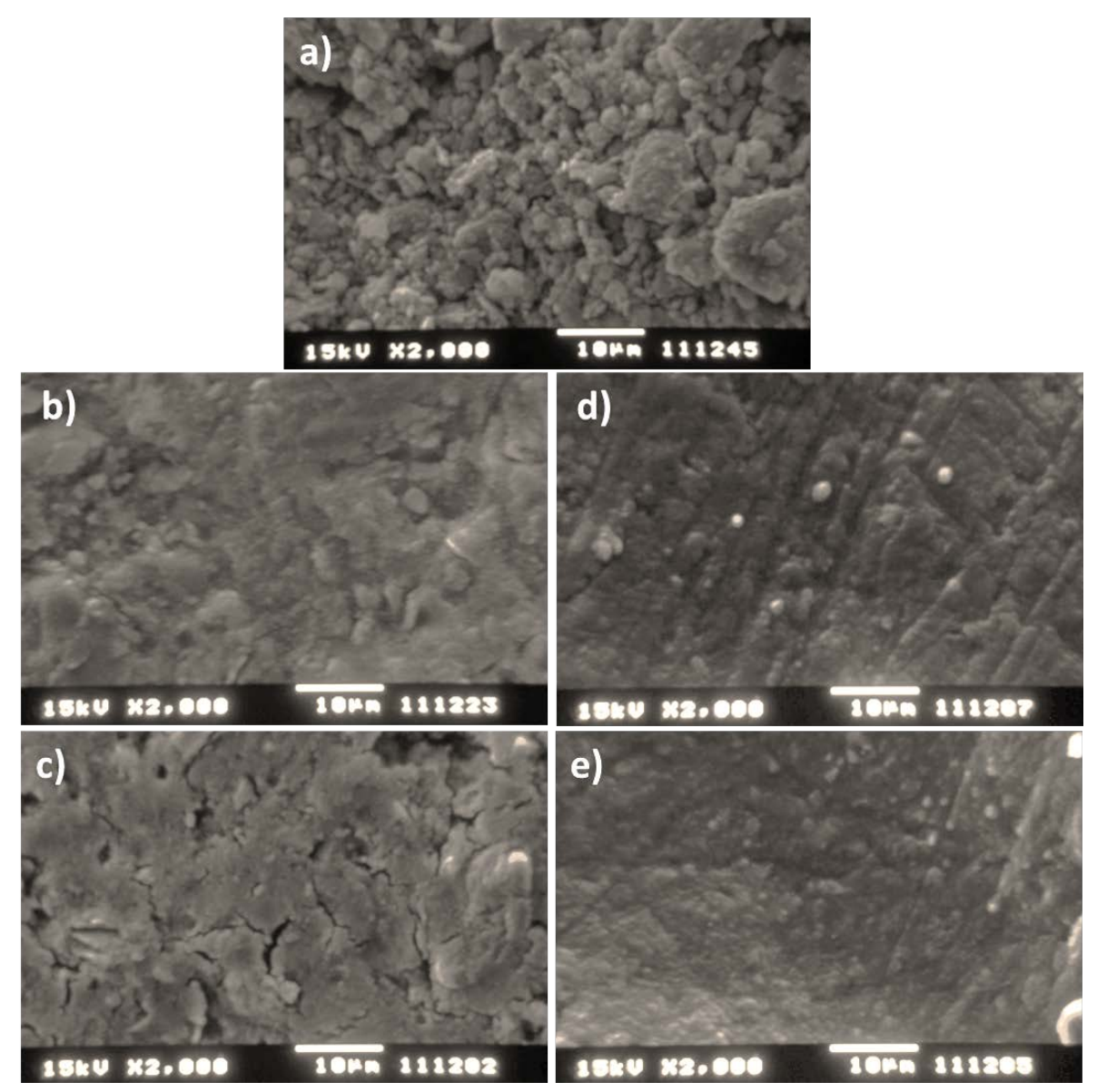

Figure 2. SEM micrographs of the metakaolin based geopolymers: a) GP-1; b) GP-2; c) GP-3; d) GP-4 and e) GP-5.

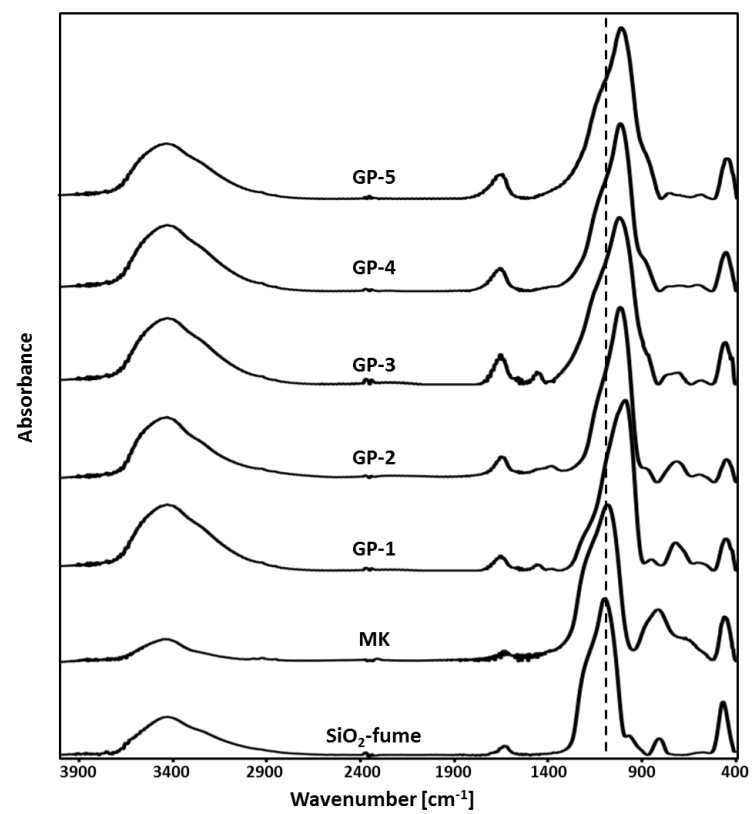

Figure 3. FTIR spectra of raw material and synthesized metakaolin based geopolymers. 


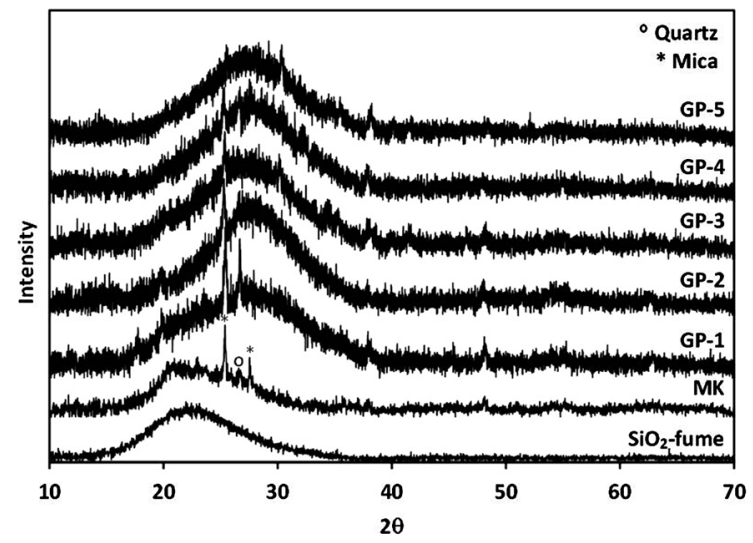

Figure 4. XRD results of raw material and metakaolin based geopolymers.

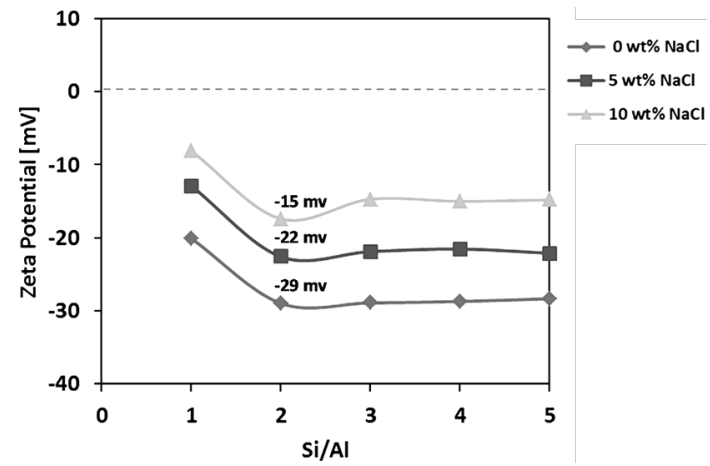

Figure 5. Zeta potential in function of the ratio of $\mathrm{Si} / \mathrm{Al}$ of metakaolin based geopolymer with $(\bullet) 0 \mathrm{wt} \% \mathrm{NaCl}$, (•) $5 \mathrm{wt} \% \mathrm{NaCl}$ and (A) $10 \mathrm{wt} \% \mathrm{NaCl}$ at $\mathrm{pH} 5$.

zeta potential was changed from $-29 \mathrm{mV},-22 \mathrm{mV}$ and $-15 \mathrm{mV}$ with a $[\mathrm{NaCl}]=0,5$ and 10 wt \% concentration, respectively. This behavior indicated that the negatively charge was electro-statically shielded by the added salt.

\subsection{Adsorption Studies of Metakaolin-Based}

The amount of silica fume in the metakaolin based geopolymers adsorbents has a strong influence on the ad-sorption process. Figure 6 shows the analysis of Langmuir isotherms for single component of metal ion (Figure 6(a)) and multicomponent solution (Figure 6(b)) of metal ions of $\mathrm{Pb}^{2+}, \mathrm{Cu}^{2+}, \mathrm{Cd}^{2+}, \mathrm{Ni}^{2+}, \mathrm{Zn}^{2+}$ and $\mathrm{Cs}^{+}$ adsorbed by geopolymers. For Figure 6(a) was observed that the adsorption by GP-2 for $\mathrm{Pb}^{2+}, \mathrm{Cu}^{2+} \mathrm{and} \mathrm{Cs}^{+}$ predominated to comparison of $\mathrm{Cd}^{2+}, \mathrm{Ni}^{2+}$ and $\mathrm{Zn}^{2+}$ which were less than the former ion group. At $\mathrm{pH} 5, \mathrm{~Pb}^{2+}$ could be present as $\mathrm{Pb}(\mathrm{OH})^{+}, \mathrm{Pb}_{2}(\mathrm{OH})^{3+}, \mathrm{Pb}_{3}(\mathrm{OH})_{4}{ }^{2+}$ and $\mathrm{Pb}_{4}(\mathrm{OH})_{4}{ }^{4+}$ but just in a small amounts [38]. However, the experiments of adsorption for $\mathrm{Pb}^{2+}$ could not be performed beyond $\mathrm{pH} 6.0$ due to the low solubility of $\mathrm{Pb}^{2+}$ hydroxide [39] in water, because the lead component is formed as white precipitation at that pH. Therefore, the adsorption test was carried out at pH 5. In contrast, the multicomponent system Figure 6(b) showed that the removal of $\mathrm{Pb}^{2+}$ and $\mathrm{Cs}^{+}$increased considerately, especially for $\mathrm{Cs}^{+}$ion. This comparison between Figure 6(a) and Figure 6(b) meant that the geopolymer had selective binding for $\mathrm{Cs}^{+}$. As a result, the adsorption selectivity of GP-2 for a mixture of metal ions was in the following order $\mathrm{Cs}^{+}>\mathrm{Pb}^{2+}>\mathrm{Cu}^{2+}>\mathrm{Zn}^{2+}>\mathrm{Ni}^{2+}>\mathrm{Cd}^{2+}$.

Figure 7 shows adsorption behavior of $\mathrm{Pb}^{2+}$ for several geopolymers at different $\mathrm{Si} / \mathrm{Al}$ ratio. It was noted that the GP-2 presented better adsorption for $\mathrm{Pb}^{2+}$, in comparison with the GP-1 which containing higher $\mathrm{Al}$ amount in the framework, so that the adsorption for $\mathrm{Pb}^{2+}$ ions decreases. It is very interesting to study salt effect of adsorption behavior of the geopolymers. As shown in the results of zeta potential, negative value supported the presence of negatively electrostatic force on the geopolymers. In Table 3 for GP-2, the effect of the addition of 


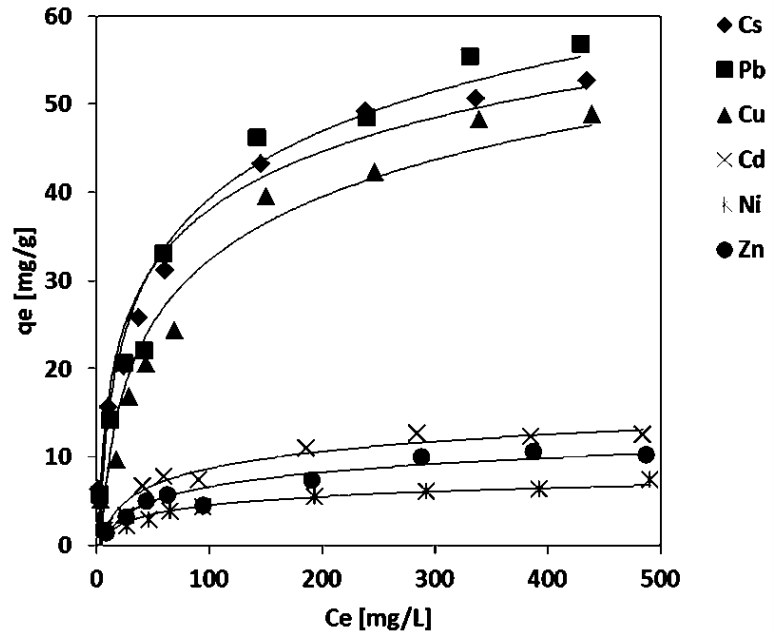

(a)

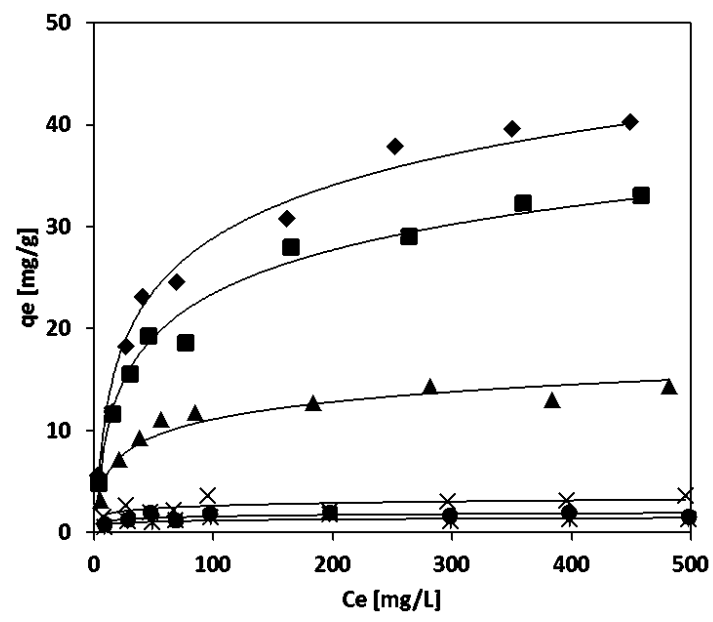

(b)

Figure 6. Langmuir isotherms for the adsorption of a) individual metal ions solution and b) mixture of multicomponent of metal ions by GP-2.

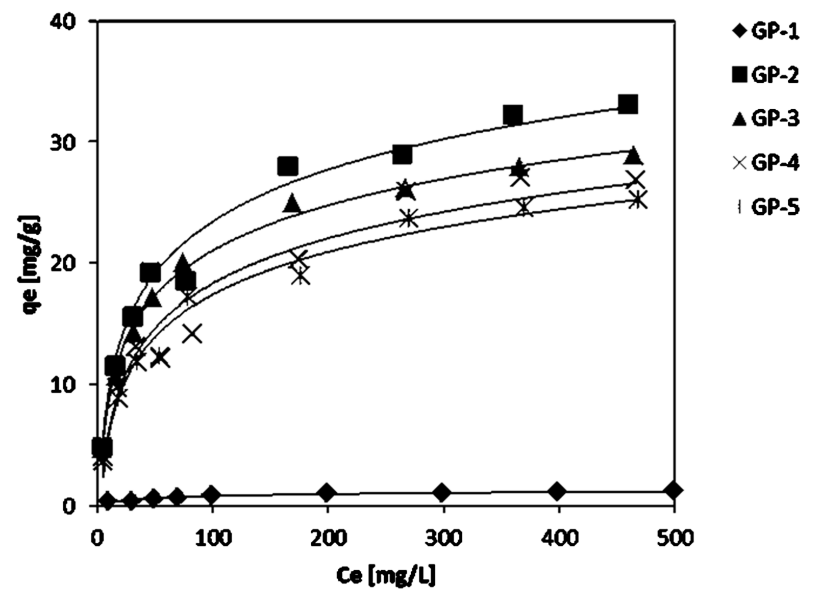

Figure 7. Langmuir isotherms for the adsorption of $\mathrm{Pb}^{2+}$ by metakaolin based adsorbents a $\mathrm{pH} 5$. 
Table 3. NaCl addition to multi-component solution for the adsorption capacity of heavy metal by GP-2.

\begin{tabular}{cccc}
\hline Metal Ion & $0 \mathrm{wt} \% \mathrm{NaCl} q_{m}[\mathrm{mg} / \mathrm{g}]$ & $5 \mathrm{wt} \% \mathrm{NaCl} q_{m}[\mathrm{mg} / \mathrm{g}]$ & $10 \mathrm{wt} \% \mathrm{NaCl} q_{m}[\mathrm{mg} / \mathrm{g}]$ \\
\hline $\mathrm{Cs}^{+}$ & 43 & 42 & 43 \\
$\mathrm{~Pb}^{2+}$ & 35 & 34 & 35 \\
$\mathrm{Cu}^{2+}$ & 15 & 13 & 15 \\
$\mathrm{Cd}^{2+}$ & 3 & 3 & 3 \\
$\mathrm{Ni}^{2+}$ & 1 & 1 & 1 \\
$\mathrm{Zn}^{2+}$ & 2 & 2 & 2 \\
\hline
\end{tabular}

$\mathrm{NaCl}$ was tested with a concentration of $5 \mathrm{wt} \%$ and $10 \mathrm{wt} \%$ on the $\mathrm{m}$ Table 3 mixture solution of metal ions. It is worth noting that the salt effect does not affect considerably in the adsorption of metal ions. For example, $\mathrm{Cs}^{+}$was adsorbed on the geopolymer with $q_{m}=43,42$ and $43 \mathrm{mg} / \mathrm{g}$ for $[\mathrm{NaCl}]=0 \mathrm{wt} \%$, $5 \mathrm{wt} \%$ and $10 \mathrm{wt} \%$, respectively. Similarly, insignificant changes were observed for the maximum adsorption by GP-2 of $\mathrm{Pb}^{2+} \mathrm{and} \mathrm{the}^{2}$ other metal ions with the increment of $\mathrm{NaCl}$ concentration as shows in Figure 8. As seen, the metal ions adsorption by geopolymer at $\mathrm{pH} 5$ was indicated that sodium concentration had no effect on the adsorption of the heavy metal ions. This meant that the heavy metal ions captured by geopolymer might be due to the less effect of electrostatic mechanism. Langmuir equation with Sacatchard analisys was used for geopolymer adsorbents in modeling of the isotherm data for the multi-component solution containing $\mathrm{Cs}^{+}, \mathrm{Pb}^{2+}, \mathrm{Cu}^{2+}, \mathrm{Cd2}^{+}, \mathrm{Ni}^{2+}$ and $\mathrm{Zn}^{2+}$. The experimental isotherms are useful for describing adsorption capacity to facilitate evaluation of the feasibility of this process. The isotherm measures the relation between the equilibrium concentration of the adsorbate in the solid phase $q_{e}[\mathrm{mg} / \mathrm{g}]$ and the equilibrium concentration in the aqueous phase $C e(\mathrm{mg} / \mathrm{L})$ [40]. As known, various mathematical transformations of the classical Langmuir equation, $q_{e}=\left(q_{m} K_{b} C_{e}\right) /\left(1+K_{b} C_{e}\right)$, are presented and then, the analysis having transformations of $C_{e} / q_{e}$ versus qe, providing various useful graphical demonstration manners [41] [42]. The Scatchard transformation can give more compact information about affinity phenomena of sorbent toward analyte. In the present study, the experimental data was applied to the Scatchard transformation was represented by the following equation [43].

$$
\frac{q_{e}}{C_{e}}=q_{m} K_{b}-q_{e} K_{b}
$$

where $q_{m}$ is theoretical maximum sorption capacity of sorbent for target solute to form a complete monolayer, and $K_{b}$ is the constant related to affinity between sorbent and sorbate.

The parameters calculated from the Scatchard plots are collectively listed in Table 4. As seen, Langmuir isotherm model was useful for characterization of specific bindings, because it mainly deal with sorption on specific binding sites. The Scatchard plot analysis for GP-2 is shown in Figure 9. The Scatchard plot is widely used technique in evaluating the affinities of binding sites taking role in a particular adsorption process. As can be seen, the deviation tendency in the plot from the linearity portion resulted in two independent sets in the data. This phenomenon indicated presence of at least two types of binding sites having different affinities toward the metal ions in the geopolymer system. So, the geopolymer adsorbent has high-affinity and low-affinity sites for $\mathrm{Cs}^{+}$and $\mathrm{Pb}^{2+}$ ions. Hence, the observed linear data were believed to be separately related to different specific bindings. The separately calculated isotherm parameters are tabulated in Table 4. Here, two different specific binding types of metal ions on the geopolymer were found to be observable at $\mathrm{pH} 5$ as designated with $\mathrm{H}$ and $\mathrm{L}$, representing high and low affinity. It can be suggested that the specific binding sites of $\mathrm{Cs}^{+}$and $\mathrm{Pb}^{2+}$ were contained mainly in the geopolymer. This information can be useful in design of novel separation techniques based on adsorption process for selective removal metal ions from waste water. Therefore, furthermore, research would be on the progress on the clear explanation of the adsorption behavior. Additionally, it was interesting to note that in Figure 6 the high binding $\mathrm{Pb}^{2+}$ ion was observed in the single ion system (Figure 6(a)), but the order in $\mathrm{Pb}^{2+}$ and $\mathrm{Cs}^{+}$was changed for the multicomponent system (Figure 6(b)). This meant that predominant adsorption to $\mathrm{Cs}^{+}$was occurred in the geopolymer adsorbent, when $\mathrm{Pb}^{2+}$ and $\mathrm{Cs}^{+}$were competed in the adsorption. As mentioned, the Scatchard analysis of $q_{m}$ and $K_{b}$ were supported the strong $\mathrm{Cs}^{+}$binding to the geopolymers. 


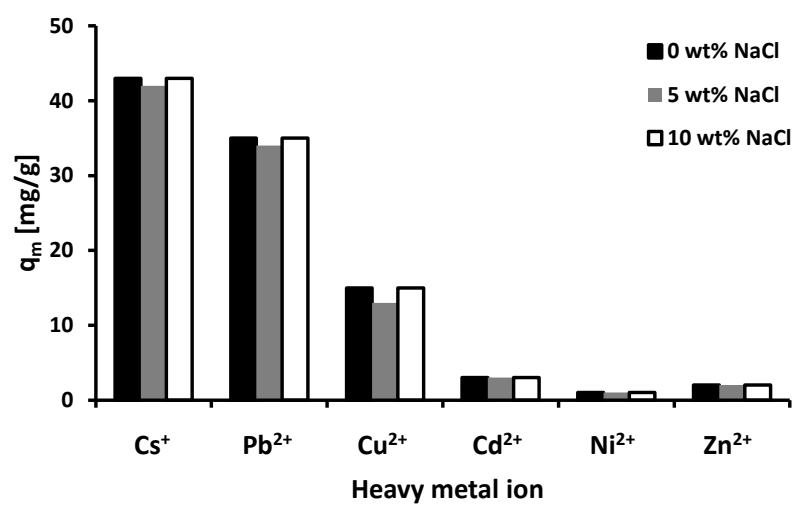

Figure 8. Maximum adsorption capacity $\left(\mathrm{q}_{\mathrm{m}}\right)$ of heavy metal ions by GP-2 with different concentration of $\mathrm{NaCl}$. ( $) 0$ wt\% $\mathrm{NaCl},(\square)$ $5 \mathrm{wt} \% \mathrm{NaCl}$ and (口) $10 \mathrm{wt} \% \mathrm{NaCl}$ at $\mathrm{pH} 5$.

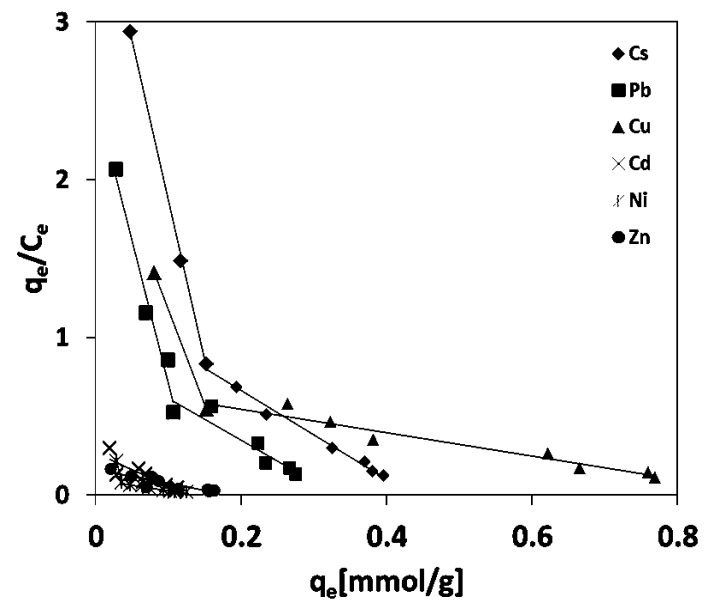

Figure 9. The Scatchard plot analysis for GP-2 at pH 5.

Table 4. Isotherm parameters of Scatchard plot.

\begin{tabular}{ccccc}
\hline Metal & \multicolumn{2}{c}{$\boldsymbol{q}_{\boldsymbol{m}}[\boldsymbol{\mu \mathrm { mol } / \mathrm { g } ]}$} & \multicolumn{2}{c}{$\boldsymbol{K}_{\boldsymbol{b}}[\mathbf{L} / \mathbf{m o l}]$} \\
\hline Ion & $\mathbf{H}$ & $\mathbf{L}$ & $\mathbf{H}$ & $\mathbf{L}$ \\
\hline $\mathrm{Cs}^{+}$ & 193 & 435 & 20000 & 2810.5 \\
$\mathrm{~Pb}^{2+}$ & 139 & 306 & 18000 & 3745.4 \\
$\mathrm{Cu}^{2+}$ & 197 & 932 & 12000 & 743.4 \\
$\mathrm{Cd}^{2+}$ & --- & --- & --- & --- \\
$\mathrm{Ni}^{2+}$ & --- & --- & --- & --- \\
$\mathrm{Zn}^{2+}$ & --- & --- & --- & --- \\
\hline
\end{tabular}

The " $H$ " and "L" symbols represent particular parameters for high- and low-affinity bindings, respectively.

\section{Conclusion}

On the ability of metakaolin-based geopolymers, the removal of $\mathrm{Cs}^{+}$and $\mathrm{Pb}^{2+}$ with heavy ion mixture of $\mathrm{Cu}^{2+}$, $\mathrm{Cd}^{2+}, \mathrm{Ni}^{2+}$ and $\mathrm{Zn}^{2+}$ was conducted from aqueous solution of mixed heavy metals. The adsorbent behavior was examined as function of the $\mathrm{Si} / \mathrm{Al}$ ratio in the geopolymer matrix and optimized at $\mathrm{Si} / \mathrm{Al}=2$. The geopolymer worked well for the separation of $\mathrm{Pb}^{2+}$ and $\mathrm{Cs}^{+}$on the mixture solution of metal ions. The value of the adsorption 
capacity increased in the following order: $\mathrm{Cs}^{+}>\mathrm{Pb}^{2+}>\mathrm{Cu}^{2+}>\mathrm{Cd}^{2+}>\mathrm{Ni}^{2+}>\mathrm{Zn}^{2+}$ for the mixture of the multicomponent system, while the individual experiment showed higher adsorption in $\mathrm{Pb}^{2+}$ relative to $\mathrm{Cs}^{+}$. Langmuir adsorption model was used for analyzing the efficiency of adsorption of the metal ions onto geopolymers. This suggested that the geopolymer adsorbents have a high selectivity for $\mathrm{Cs}^{+}$ion. Salt effect on the adsorption behavior indicated that the selectivity was due to the electrostatic force of charged sites of the geopolymers. For evaluating the type of interactions between metal ions and metakaolin-based geopolymer, further research would be in progress in near future.

\section{References}

[1] Matis, K.A., Zouboulis, A.I. and Lazaridis, N.K. (1998) Removal and Recovery of Metals from Dilute Solutions: Applications of Flotation Techniques. Mineral Processing and the Environment, 43, 165-196. http://dx.doi.org/10.1007/978-94-017-2284-1_9

[2] Hui, K.S., Chao, C.Y.H. and Kot, S.C. (2004) Removal of Mixed Heavy Metal Ions in Wastewater by Zeolite 4A and Residual Products from Recycled Coal Fly Ash. Journal of Hazardous Materials, 127, 89-101. http://dx.doi.org/10.1016/j.jhazmat.2005.06.027

[3] Brauckmann, B.M. (1990) Industrial Solutions Amenable to Biosorption. In: Volesky, B., Ed., Biosorption of Heavy Metals, CRC Press, Boca Raton, Vol. 52.

[4] López, F.A., Martín, M.I., Pérez, C., López-Delgado, A. and Alguacil, F.J. (2003) Adsorción de Metales Pesados Sobre Cascarilla de Laminación. Revista Metalurgia, 39, 215-223. http://dx.doi.org/10.3989/revmetalm.2003.v39.i3.332

[5] Buchwald, A., Zellmann, H.D. and Kaps, Ch. (2011) Condensation of Aluminosilicate Gels-Model System for Geopolymer Binders. Journal of Non-Crystalline Solids, 357, 1376-1382. http://dx.doi.org/10.1016/j.jnoncrysol.2010.12.036

[6] Komnitsas, K. and Zaharaki, D. (2007) Geopolymerisation: A Review and Prospects for the Minerals Industry. Minerals Engineering, 20, 1261-1277. http://dx.doi.org/10.1016/j.mineng.2007.07.011

[7] Xu, H. and Van Deventer, J.S.J. (2002) Microstructural Characterisation of Geopolymers Synthesised from Kaolinite/Stilbite Mixtures Using XRD, MAS-NMR, SEM/EDX, TEM/EDX, and HREM. Cement and Concrete Research, 32, 1705-1716. http://dx.doi.org/10.1016/S0008-8846(02)00859-1

[8] Barbosa, V.F.F. and MacKenzie, K.J.D. (2003) Synthesis and Thermal Behaviour of Potassium Sialate Geopolymers. Materials Letters, 57, 1477-1482. http://dx.doi.org/10.1016/S0167-577X(02)01009-1

[9] Xu, H. and Van Deventer, J.S.J. (2000) The Geopolymerisation of Alumino-silicate Minerals. International Journal of Mineral Processing, 59, 247-266. http://dx.doi.org/10.1016/S0301-7516(99)00074-5

[10] Prud'homme, E., Michaud, P., Joussein, E., Peyratout, C., Smith, A. and Rossignol, S. (2011) In Situ Inorganic Foams Prepared from Various Clays at Low Temperature. Applied Clay Science, 51, 15-22. http://dx.doi.org/10.1016/j.clay.2010.10.016

[11] Zhang, Y.J., Li, S., Wang, Y.C. and Xu, D.L. (2012) Microstructural and Strength Evolutions of Geopolymer Composite Reinforced by Resin Exposed to Elevated Temperature. Journal of Non-Crystalline Solids, 358, 620-624.

[12] Duxson, P., Fernández-Jiménez, A., Provis, J.L., Lukey, G.C., Palomo, A. and Van Deventer, J.S.J. (2007) Geopolymer Technology: The Current State of the Art. Journal of Materials Science, 42, 2917-2933. http://dx.doi.org/10.1007/s10853-006-0637-z

[13] Goretta, K.C., Gutierrez-Mora, F., Singh, D., Routbort, J.L., Lukey, G.C. and Van Deventer, J.S.J. (2007) Erosion of Geopolymers Made from Industrial Waste. Journal of Materials Science, 42, 3066-3072. http://dx.doi.org/10.1007/s10853-006-0561-2

[14] Kong, D.L.Y., Sanjayan, J.G. and Sagoe-Crentsil, K. (2007) Comparative Performance of Geopolymers Made with Metakaolin and Fly Ash After Exposure to Elevated Temperatures. Cement and Concrete Research, 37, 1583-1589. http://dx.doi.org/10.1016/j.cemconres.2007.08.021

[15] Yip, C.K., Lukey, G.C. and Van Deventer, J.S.J. (2004) Effect of Blast Furnace Slag Addition on Microstructure and Properties of Metakaolinite Geopolymeric Materials. Ceramic Transactions, 153, 187-209.

[16] Cheng, T.W., Lee, M.L., Ko, M.S., Ueng, T.H. and Yang, S.F. (2012) The Heavy Metal Adsorption Characteristics on Metakaolin-Based Geopolymer. Applied Clay Science, 56, 90-96. http://dx.doi.org/10.1016/j.clay.2011.11.027

[17] Li, L., Wang, S.B. and Zhu, Z.H. (2006) Geopolymeric Adsorbents from Fly Ash for Dye Removal from Aqueous Solution. Journal of Colloid and Interface Science, 300, 52-59. http://dx.doi.org/10.1016/j.jcis.2006.03.062

[18] Wang, S.B. and Peng, Y.L. (2010) Natural Zeolites as Effective Adsorbents in Water and Wastewater Treatment. Chemical Engineering Journal, 156, 11-24. http://dx.doi.org/10.1016/j.cej.2009.10.029

[19] Zhang, J.G., Provis, J.L., Feng, D.W. and Van Deventer, J.S.J. (2008) Geopolymers for Immobilization of $\mathrm{Cr}^{6+}$, Cd ${ }^{2+}$, 
and $\mathrm{Pb}^{2+}$. Journal of Hazardous Materials, 157, 587-598. http://dx.doi.org/10.1016/j.jhazmat.2008.01.053

[20] Ahmaruzzaman, M. (2010) A Review on the Utilization of Fly Ash. Progress in Energy and Combustion Science, 36, 327-363. http://dx.doi.org/10.1016/j.pecs.2009.11.003

[21] Lopez, F.J., Sugita, S. and Kobayahi, T. (2014) Cesium-Adsorbent Geopolymer Foams Based on Silica from Rice Husk and Metakaolin. Chemistry Letters, 43, 128-130. http://dx.doi.org/10.1246/cl.130851

[22] Palomo, A., Blanco Varela, M.T., Granizo, M.L., Puertas, F., Vázquez, T. and Grutzeck, M.W. (1999) Chemical Stability of Cementitious Materials Based on Metakaolin. Cement and Concrete Research, 29, 997-1004. http://dx.doi.org/10.1016/S0008-8846(99)00074-5

[23] Granizo, M.L., Blanco-Varela, M.T. and Palomo, A. (2000) Influence of the Starting Kaolin on Alkali-Activated Materials Based on Metacaolin. Study of the Reaction Parameters by Isothermal Conduction Calorimetry. Journal of Materials Science, 35, 6309-6315. http://dx.doi.org/10.1023/A:1026790924882

[24] Moenke, H.H.W. (1994) Silica, the Three-Dimensional Silicates, Borosilicates and Beryllium Silicates. In: Farmer, V.C., Ed., The Infrared Spectra of Minerals, Mineralogical Society Monograph 4, Adlard \& Son, Dorking, Surrey, 365.

[25] Parker, R.W. and Frost, R.L. (1996) The Application of Drift Spectroscopy to the Multicomponent Analysis of Organic Chemicals Adsorbed on Montmorillonite. Clays and Clay Minerals, 44, 32-40. http://dx.doi.org/10.1346/CCMN.1996.0440103

[26] Frost, R.L., Frederick, P.M. and Shurvell, H.F. (1996) Raman Microscopy of Some Kaolinite Clay Minerals. Canadian Journal of Applied Spectroscopy, 41, 10.

[27] Ríos, C.A., Williams, C.D. and Fullen, M.A. (2009) Nucleation and Growth History of Zeolite LTA Synthesized from Kaolinite by Two Different Methods. Applied Clay Science, 42, 446-454. http://dx.doi.org/10.1016/j.clay.2008.05.006

[28] Giannopoulou, I. and Panias, D. (2010) Hydrolytic Stability of Sodium Silicate Gels in the Presence of Aluminum. Journal of Materials Science, 45, 5370-5377. http://dx.doi.org/10.1007/s10853-010-4586-1

[29] Gadsen, J.A. (1995) Infra-Red Spectra of Minerals and Related Inorganic Compounds. Butterworth, London.

[30] Farmer, V.C. (1994) The Infrared Spectra of Minerals. Mineralogical Society, London.

[31] Palomo, A. and Glasser, F.P. (1992) Chemically-Bonded Cementitiousn Material Based on Metakaolin. British Ceramic Transactions, 91, 107-112.

[32] Madani, A. (1990) ${ }^{29} \mathrm{Si}$ and ${ }^{27} \mathrm{Al}$ NMR Study of Zeolite Formation from Alkali-Leached Kaolinites. Influence of Thermal Preactivation. Journal of Physical Chemistry, 94, 760-765.

[33] Ortego, J.D. and Barroeta, Y. (1991) Leaching Effects on Silicate Polymerisation. An FTIR and 29Si NMR Study of Lead and Zinc in Portland Cement. Environmental Science \& Technology, 25, 1171-1174. http://dx.doi.org/10.1021/es00018a024

[34] Granizo, M.L., Alonso, S., Blanco-Varela, M.T. and Palomo, A. (2010) Alkaline Activation of Metakaolin: Effect of Calcium Hydroxide in the Products of Reaction. Journal of the American Ceramic Society, 45, 607.

[35] Zhang, Y.S., Sun, W. and Li, Z.J. (2008) Infrared Spectroscopy Study of Structural Nature of Geopolymeric Products. Journal of Wuhan University of Technology, 23, 522-527. http://dx.doi.org/10.1007/s11595-007-4522-7

[36] Aveyerd, R. (1984) Adsorption at A/L, L/L and S/L Interfaces in Surfactants. In: Tadros, T.F., Ed., Academic Press, London, 166-173.

[37] Aranberri, I. and Bismarck, A. (2007) Caracterización Superficial de Minrales Arcillosos Presentes en los Depósitos de Crudo. Anales de Quimica, 103, 23-27.

[38] Sreejalekshmi, K.G., Krishnan, K.A. and Anirudhan, T.S. (2009) Adsorption of Pb(II) and Pb(II)-Citric Acid on Sawdust Activated Carbon: Kinetic and Equilibrium Isotherm Studies. Journal of Hazardous Materials, 161, 1506-1513. http://dx.doi.org/10.1016/j.jhazmat.2008.05.002

[39] Sen Gupta, S.K. and Bhattacharyya, K.G. (2008) Immobilization of Pb(II), Cd(II) and Ni(II) Ions on Kaolinite and Montmorillonite Surfaces from Aqueous Medium. Journal of Environmental Management, 87, 46-58. http://dx.doi.org/10.1016/j.jenvman.2007.01.048

[40] Purkait, M.K., Gusain, D.S., Das Gupta, S. and De, S. (2005) Adsorption Behavior of Chrysoidine Dye on Activated Charcoal and Its Regeneration Characteristics Using Different Surfactants. Separation Science and Technology, 39, 2419-2440. http://dx.doi.org/10.1081/SS-120039347

[41] Gezici, O., Kara, H., Ayar, A. and Topkafa, M. (2007) Sorption Behavior of Cu(II) Ions on Insolubilized Humic Acid Under Acidic Conditions: An Application of Scatchard Plot Analysis in Evaluating the pH Dependence of Specific and Nonspecific Bindings. Separation and Purification Technology, 55, 132-139. http://dx.doi.org/10.1016/j.seppur.2006.11.012 
[42] Scatchard, G. (1949) The Attraction of Proteins for Small Molecules and Ions. Annals of the New York Academy of Sciences, 51, 660-672. http://dx.doi.org/10.1111/j.1749-6632.1949.tb27297.x

[43] Bhattacharya, A.K. and Venkobachar, C. (1984) Removal of Cadmium (II) by Low Cost Adsorbents. Journal of Environmental Engineering, 110, 110-122. http://dx.doi.org/10.1061/(ASCE)0733-9372(1984)110:1(110) 
Scientific Research Publishing (SCIRP) is one of the largest Open Access journal publishers. It is currently publishing more than 200 open access, online, peer-reviewed journals covering a wide range of academic disciplines. SCIRP serves the worldwide academic communities and contributes to the progress and application of science with its publication.

Other selected journals from SCIRP are listed as below. Submit your manuscript to us via either submit@scirp.org or Online Submission Portal.
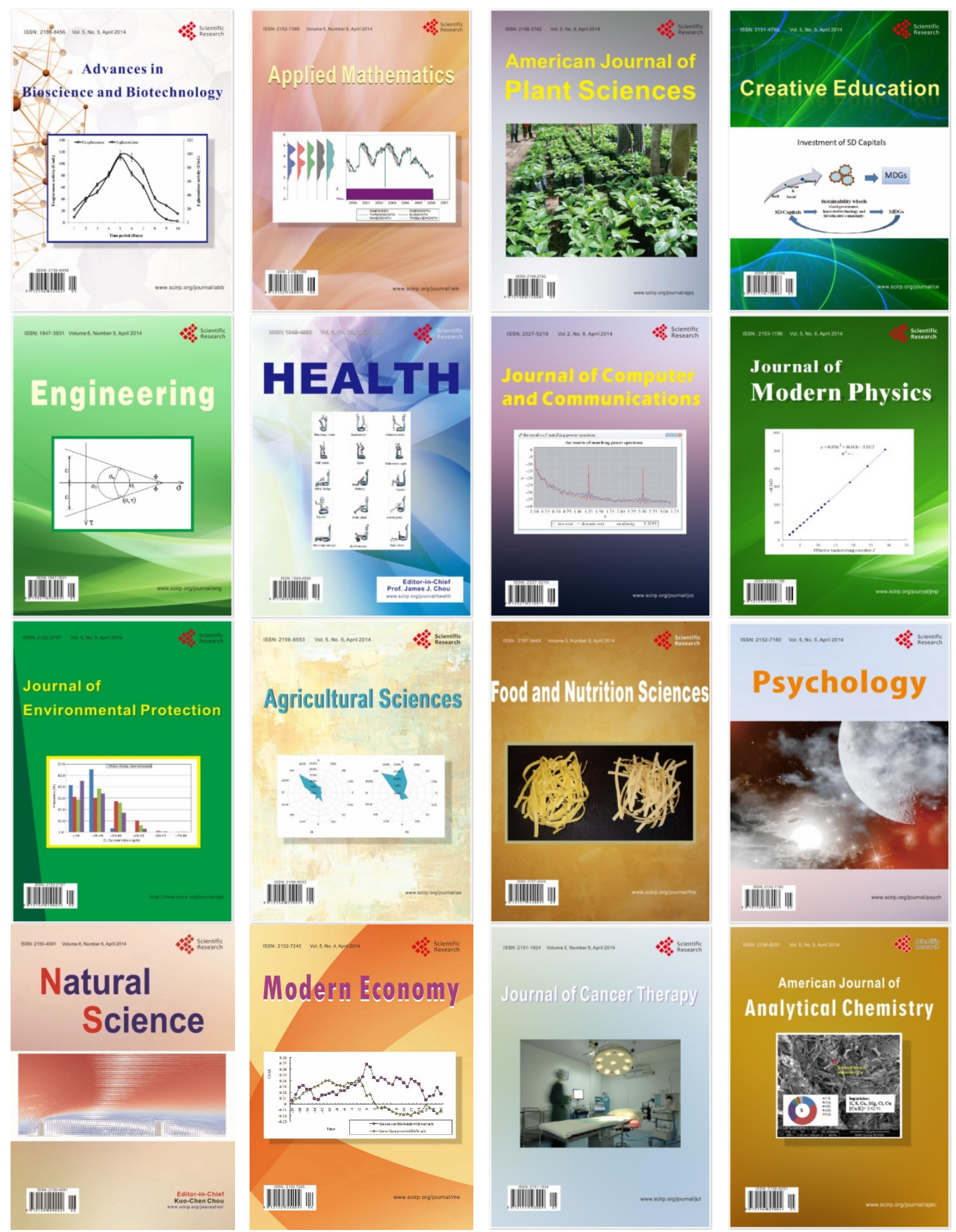